\title{
The green metropolis generator: developer's toolkit for urban landscape in the Green
}

\author{
J. Jonkhof ${ }^{1}$, W. Timmermans ${ }^{2}$ \& V. Kuypers ${ }^{2}$ \\ ${ }^{I}$ Wageningen University Research, Wageningen, The Netherlands \\ ${ }^{2}$ Alterra, Wageningen, The Netherlands
}

\begin{abstract}
In this paper, a method is developed to identify a typology of interrelated landscapes in the urban-rural realm, in order to describe the connection between landscape characteristics, natural environment characteristics and ecological strategies, finally translated into spatial planning styles. This interrelated complex of physical, social and managerial concepts may at first seem unusual, but the authors are convinced that this approach provides a useful insight. That one of the great challenges for planners today is to connect the best of two worlds: the one actually focussing on differentiation in governance style in the field of planning concepts, as well the one focussing the debate on landscape ecology on connectivity in spatial structures as the key towards sustainability in both nature development and sustainable urban planning.

Keywords: typology, landscape, spatial planning, nature development, urban planning, urban-rural relationship, delta metropole.
\end{abstract}

\section{Preamble}

\subsection{Problem definition: the quest for a versatile approach}

In this paper we will discuss the problem of dealing with the paradox of environmental planning: the best and most innovative planning solutions develop under the most severe conditions and stress accumulation. At the global scale, these conditions can actually be found largely in metropolitan areas at the confines of various large river systems, like Shanghai with the Yellow river system, the Antwerp-Rotterdam-Ruhr area with the Dutch estuary complex of Rhine, Scheldt and Meuse river systems, New York with the Hudson bay system, 
the Ganges flood river system in Bangla Desh, emerging areas like the Bangkok area in the Chao Phraya river system but also complex areas like New Orleans with the Mississippi river system, (Van Susteren, [19]). Focussing on the European planning tradition, the Antwerp-Rotterdam-Ruhr area is the source of many planning and governance concepts concerning the development of large metropolitan areas. In planning history, the Netherlands did play a leading role in that perspective. Starting in the $17^{\text {th }}$ century, the development of the small historical multi-focal urban node has lead to the growth of the utterly scattered urban development we see actually today - the Randstad, in fact a multi-purpose, multi-functional, multi-cultural urban development that for many historians, geographers, planners and utopists is more and more a source of inspiration (Schama [16], Hall [4]). This deliberate urban multi-nodal approach today generates the power of versatile response to a large set of problems concerning the need for innovative solutions on a large variety of themes. One of the emerging themes is the perspective of urban nodal decline in the next decades of the 21 st century, to the benefit of increasing urban development of rural areas towards large urbanised physical and virtual networks, thus creating the very spectre of ecological, social and economic challenges we could possibly imagine (Harvey [5], Castells [3]).

\subsection{Discussion and conclusion: green metropolis, a breed for research}

The very characteristics of the Green metropolis provide a challenging substrate, so to speak a prolific "ecology" for innovative research practice and culture. This type of connective research could develop towards a new research practice (De Jonge and Jonkhof, [10]). The Green-approach of the Wageningen research school does actually reflect an image of such an approach. The very subject of this 'breed' of research and design practitioners is the Green metropolis! On the premises of our analysis, we do actually propose a Developers Tool Kit for Urban landscape in metropolitan areas.

\section{Developers toolkit for Urban landscape in Delta Metropolis}

\subsection{Introduction}

The Delta Metropolis is being fed with by a system of watersheds. Within this system we can make a distinction between five environments, on the basis of the difference in design of the relationship between the built and the green environments.

We describe the gradient starting from the source areas up hill, via the Mainland and the low stream areas, towards the costal zones and finally the sea and shore area, the 'pre-delta' zones.

Following this gradient, the typology of the relationship between city and nature is actually varying strongly. We do describe this variation in terms of both spatial and temporal order, that is to say in terms of both patterns and processes. With this variation, also the ecological strategies underlying the different 
planning styles do vary as well. We do propose several metaphors describing these different combinations and by doing so, we try to get a better grip on the complex relationships between urban development, natural development and planning culture in the Delta Metropolis.

Finally, we do open a perspective view on a pallet of planning styles, each of the styles fitting to the different situational aspects of the different landscapes in the Delta Metropolis.

\subsection{About city and nature}

\subsubsection{Highland}

In highland we find a rural area, relatively large areas for nature (woods) in a low-dynamic ecological system, characterized by a high internal richness of patterns: spread out living environments, food production, raw materials resources (timber, energy) and recreational residence. Here we discover the source areas for the delta.

Planning does aim here at a delicate equilibrium between culture and nature and is being defined by an ecological strategy of the type 'regularly taking measures on small scale locations'.

Mind: the effects of the measures do have repercussions on the entire catchment area. The metaphor for the cultural end-picture, the romantic and static image that the urban inhabitants of this landscape do cherish is: ARCADIA!

2.2.1.1 Discussion Highland does deliver - just do consider the occurring natural erosion processes - the natural resources for the next landscapes: the lowland and the Delta. But Arcadia is self sufficient and conservative: it will urge for the conservation of its image. While the spatial variation is actively tending towards nivellation, Arcadia will build dams and obstacles to prevent this and keep the dream alive. What is wise: freehand for nature or freehand for Arcadia...?

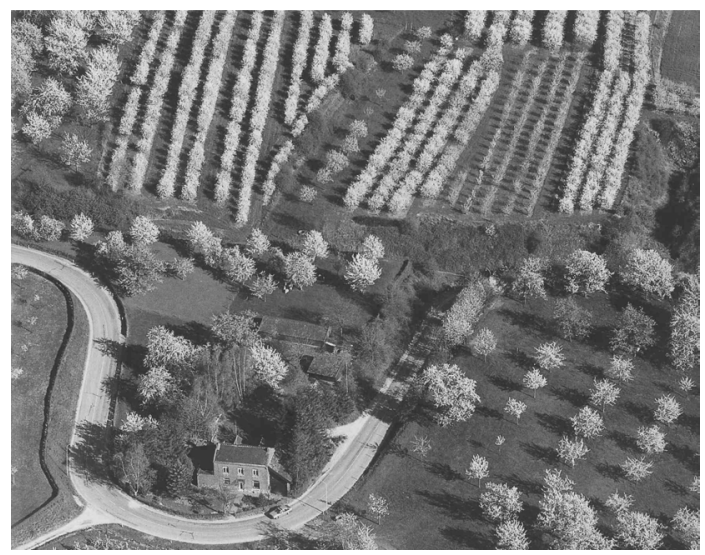

Figure 1: Impression Highland / Arcadia. 


\subsubsection{Mainland}

In Mainland we have to deal with a park city like living environment, for the middle classes, that is to say a relatively spacious green living environment with spread out concentrations of amenities, nodal points with a fine maze of accessibility facilities: SUBURBIA! The pattern of space use for nature and for urban uses is the uncertain outcome of a permanent conflict, being battled out with claiming space techniques.

After relatively stable periods, thresholds are being trespassed again, resulting in large-scale substitution processes: agriculture $>$ urban space, natural areas $>$ water, natural areas $>$ urban areas, wetlands $>$ leisure areas, and so on.

The ecological strategy here is actually being focussed on the prediction and control of these transformations, applying measures accordingly of the type: 'unique large scale operations', that is to say: investing in growth in a few large steps, both in the rural areas (nature development projects, water storage projects) as in the city (city development, restructuration projects). This leads towards relatively strongly controlled environments with created 'pockets' of distinct ecosystems, which, once they are in place, can develop under stable conditions. The actual national policy for the green space in and around cities in the Netherlands for instance is a good illustration for this approach.

Cities in Mainland are in first stages of the bastide type: rather compact because of the physical conditions of their location, situated within spacey and green outer space, on nodal points in the local infrastructure. In later stages, better accessibility is occurring and leaves the way to the growth of network cities and more complex agglomerations of cities, open space, woods and leisure grounds, with enough extra space for water storage, energy winning and connecting infrastructure. In the most probable scenario, a combination of internal variation - for instance in the architectural features - and external variation, especially on the urban level, is occurring. A better scenario would be the one with better variation in spatial and temporal dynamics.

It is remarkable that in Mainland the current national environmental policy finds its origins: in this environment we find the must urge for control en management. For instance: the reduction of uncertainty about future use of space, about wanted spatial quality, about property values, about security in the public space and so on. Nature development takes place in 'pockets': remains of formerly coherent and complex landscape ecological structures, like ombrotrophic highland moors and blue grasslands.

In the rural areas the agriculture is the most important agent, but it will get in conflict with urban development. On the transition zones between Mainland and Highland, we find special environments, such as large estates, mansions and rural housing.

2.2.2.1 Discussion It belongs to the heritage of Sustainable Development in Suburbia to give high priority to the safeguard of 'stocks' like food, space, nature and resources by control and management. However, this requires a new vision on central governance, and on the relationship between the fulfilment of 
individual needs and the very safeguarding of collective (public) values. For these items, we will still need more support. To put it strongly: the support for it is even diminishing actually.

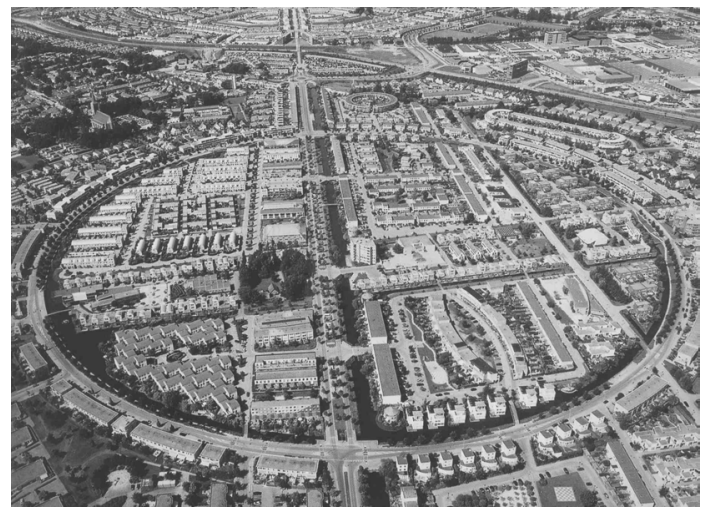

Figure 2: Impression Mainland / Suburbia.

\subsubsection{Chain of cities}

This is the urban zone, with high densities of housing, working places, and communicative structures: AGORA! All use of available space is 'locked'. Within the actual use of space, we find a large internal dynamic evolution, both spatial as temporal, and a continuous substitution of forms of space use, in the first stages merely conditioned by social engineering based on control and management (Cities in Europe, Eastern Europe, Middle East) and later merely based on the logics of market development (cities in Asia, South America, West Africa). Sometimes we have seen - literally - the need for an earthquake to get changes in this situation. Arguments following the impacts of the characteristics of the landscape are not tolerated being a motive for influence on the city form and city development: there is no room for insertion of new space needs for water storage, food production, infrastructure, nor for high biodiversity nature.

In order to yet satisfy the needs for such resources, they are to be found elsewhere. And, as for Nature itself, it is considered to be a cultural item, of the type 'open end': Nature can be 'invented' here. The perception of nature, highly translated into cultural connotations, is a permanent object for societal debate. This leads towards a broad spectrum of cultural strategies, with permanent small interventions and alterations, and finally towards a strategy of the type 'continuous small scale intervention at any place'. Now we get strongly varying natural qualities, with unpredictable outcome, and occasionally surprises like the emergence of new border species.

2.2.3.1 Discussion Safeguarding of the city as a cultural nursery is a 'political correct' thing to do, in social-cultural and social-economical point of view (especially in 'Old" Europe). It will lead towards a conservative attitude about planning. But societal developments will lead to an open network society and by 
doing so, to unforeseen forms of cultural and economical development (the Delta Metropolis as an important scene for globalisation). Who will win this contest?

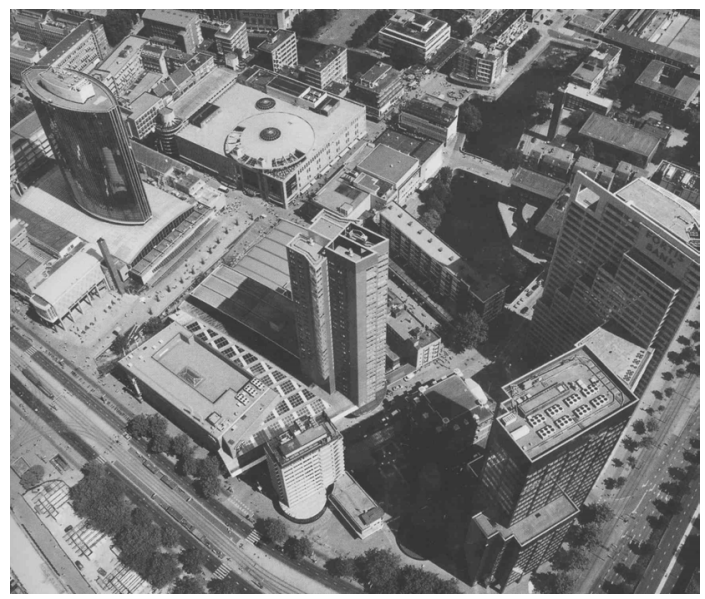

Figure 3: Impression Chain of Cities / Agora.

\subsubsection{Lowland}

In this environment we do find the traces of the first settlements (riverbanks), alongside the location of the first settlements of deregulated new communities: AUTARKIA! The scene of opinion clashes on the relationship between Culture and Nature: historicizing or modernizing, conservative or innovative? It's all about eutrophic estuaries in the river-landscape, with both highly temporal as spatial variation: high-dynamic environments, resistant to unpredicted assaults of nature events.

The ecological strategy is: 'varied measures at varied places' (as for space, pollution, penetration, digging, and so on). In the Netherlands we have corresponding policy programmes like Belvedere, Space for the rivers, the Dutch Water line etc., to illustrate this approach.

In this environment we do find space for New Nature (active nature development), potentially high quality nature, situated in so-called half-natural landscapes, stimulated by the combination of natural processes (wind and water) and societal developments such as incorporation of fast urban and economical growth. This leads towards a biodiversity type characterized by a quite important turn over of biomass and a high resistance against ecological shocks.

2.2.4.1 Discussion In Autarkia there is a surly a strong need for more space for discovering and development, but at the same time we do find a serious lack in accepting the impacts: the need for space for new activities does lead - despite the well organized coaching projects - towards fear for the unknown open ends outcomes. The actual spatial policy does stimulate these fears and aims finally at 
a conservative approach in planning and fixation on maximizing certainty, as the Dutch environmental protection ngo's do with their policy for "draw the green line" (between the 'bad' urbanization and the 'good' green spaces - JFJ).

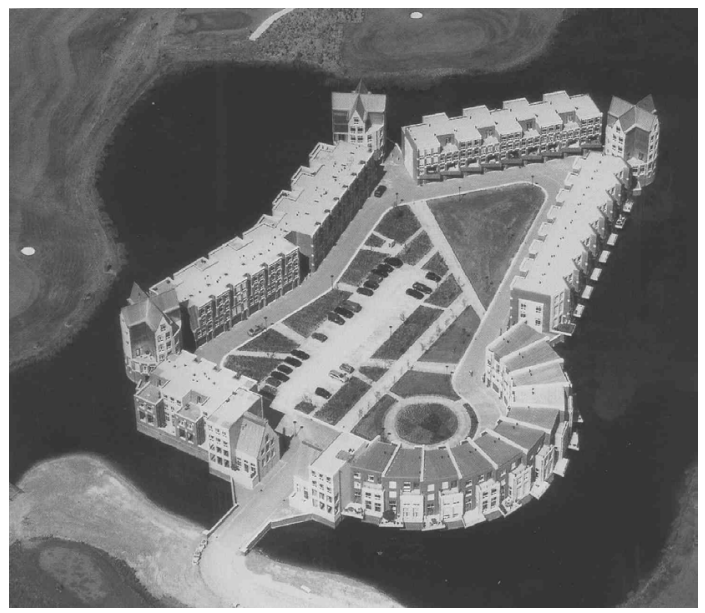

Figure 4: Impression Lowland / Autarkia.

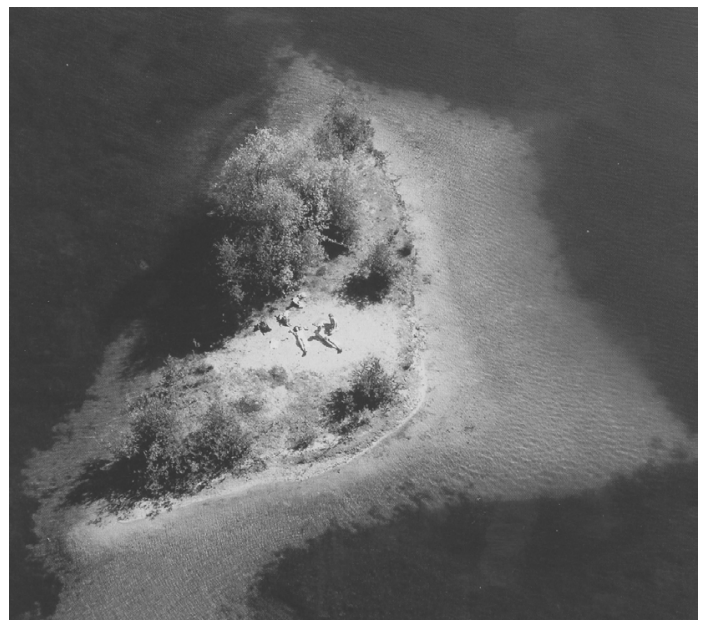

Figure 5: Impression Pre-Delta / Utopia.

\subsubsection{Pre-Delta}

Finally the series of environmental landscapes does culminate into the Pre-Delta, UTOPIA! It is the coastal landscape with new forms of relationships between water and land: the pioneers landscape of the future, settlement for new activities: winning of energy, food production, new space for new forms of infrastructure (airports), discovery space for new worlds on the borders of land and sea, backed up by the Elements. This is the development space for highly 
dynamic and robust basic ecosystems, within the framework of a strategy of the type: 'unique large scale measures on large scale locations'. These robust pioneer environments do belong here, with their important variations in patternand process variations and contrasts: land-water, salt-sweet, growth-decline.

\subsubsection{The toolkit as a DELTA METROPOLIS generator}

The toolkit for planning DELTA METROPOLIS can now be shown: the relationship between the typologies for Urbanization and for Nature development:

Table 1: The toolkit for planning DELTA METROPOLIS: a typology of de relationship between city and nature in the Delta metropolis.

\begin{tabular}{|c|c|c|c|c|c|c|}
\hline \multirow[t]{2}{*}{$\begin{array}{l}\text { Delta } \\
\text { landscapes }\end{array}$} & \multicolumn{2}{|c|}{$\begin{array}{l}\text { Urbanization } \\
\text { typology }\end{array}$} & \multicolumn{2}{|c|}{$\begin{array}{r}\text { Environmental } \\
\text { typology }\end{array}$} & \multirow[t]{2}{*}{$\begin{array}{l}\text { Ecological } \\
\text { strategies }\end{array}$} & \multirow[t]{2}{*}{ Metaphor } \\
\hline & $\mathrm{Ch}$ & acteristics & Character & istics & & \\
\hline $\begin{array}{l}\text { Highland/ } \\
\text { Upstream }\end{array}$ & S1 & $\begin{array}{l}\text { Rural housing } \\
1 \mathrm{~h} / \mathrm{ha}\end{array}$ & Source areas & N1 & $\begin{array}{l}\text { Unique } \\
\text { small scale } \\
\text { measures on } \\
\text { small scale } \\
\text { locations }\end{array}$ & $\begin{array}{l}\text { Arcadia } \\
\text { (Fig. 1) }\end{array}$ \\
\hline $\begin{array}{l}\text { Mainland/ } \\
\text { midstream } \\
\text { Parkland }\end{array}$ & S2 & $\begin{array}{l}\text { Suburb housing } \\
30 \mathrm{~h} / \mathrm{ha}\end{array}$ & $\begin{array}{r}\text { Production } \\
\text { landscape } \\
\text { agriculture } \\
\text { nature } \\
\text { urbanization }\end{array}$ & N2 & $\begin{array}{l}\text { Unique } \\
\text { large scale } \\
\text { measures }\end{array}$ & $\begin{array}{l}\text { Suburbia } \\
\text { (Fig. 2) }\end{array}$ \\
\hline $\begin{array}{l}\text { Chain of } \\
\text { Cities } \\
\text { City core }\end{array}$ & S3 & $\begin{array}{l}\text { Urban housing } \\
200 \mathrm{~h} / \mathrm{ha}\end{array}$ & Urban ecology & N3 & $\begin{array}{l}\text { Continuous } \\
\text { small scale } \\
\text { measures } \\
\end{array}$ & $\begin{array}{l}\text { Agora } \\
\text { (Fig. 3) }\end{array}$ \\
\hline $\begin{array}{l}\text { Lowland } \\
\text { Delta } \\
\text { Estuaries }\end{array}$ & S4 & $\begin{array}{l}\text { Delta living } \\
30 \mathrm{~h} / \mathrm{ha}\end{array}$ & $\begin{array}{r}\text { Nature agri- } \\
\text { culture on large } \\
\text { scale } \\
\text { depositions }\end{array}$ & N4 & $\begin{array}{l}\text { Varying } \\
\text { measures on } \\
\text { various } \\
\text { places }\end{array}$ & $\begin{array}{l}\text { Autarkia } \\
\text { (Fig. 4) }\end{array}$ \\
\hline $\begin{array}{l}\text { Coastal } \\
\text { zone } \\
\text { Pre-Delta }\end{array}$ & S5 & $\begin{array}{l}\text { Shore \& coastal } \\
\text { housing } \\
1 \mathrm{~h} / \mathrm{ha}\end{array}$ & $\begin{array}{r}\text { Dynamics of } \\
\text { rivers, sea \& } \\
\text { shore }\end{array}$ & N5 & $\begin{array}{l}\text { Unique } \\
\text { large scale } \\
\text { measures }\end{array}$ & $\begin{array}{l}\text { Utopia } \\
\text { (Fig. 5) }\end{array}$ \\
\hline
\end{tabular}

2.2.6.1 Discussion Potentially high values for development are left aside without being used, while there is struggle for space on the landside. But when solving the problems up-land is too easily found in Pre-Delta space and facilities, the consumption of space up-land will exceedingly increase. What is wise?

\subsection{About culture, planning and politics}

Above we described the typology of the relationship between City and Nature: Highland in Arcadia, midstream's Mainland in Suburbia, the Chain of Network Cities in Agora, Lowland in the delta of Autarkia and finally the shore and coastal environment of the Pre-Delta of Utopia. By introducing such metaphors, we paved the road to a more cultural approach of the typology of urban and 
natural development. In this approach planning is to be considered as a direct expression of a cultural self-consciousness. When we look at planning as a concerted action (Faludi \& Van der Valk [6]), then it is obvious to consider planning as a cultural activity, submitted to the logic of interacting cultural factors. The driving factors behind this approach are norms and the way we deal with uncertainty. Further on we draw a picture of how this approach can result in a vivid expression of the relationship between urban and natural environment.

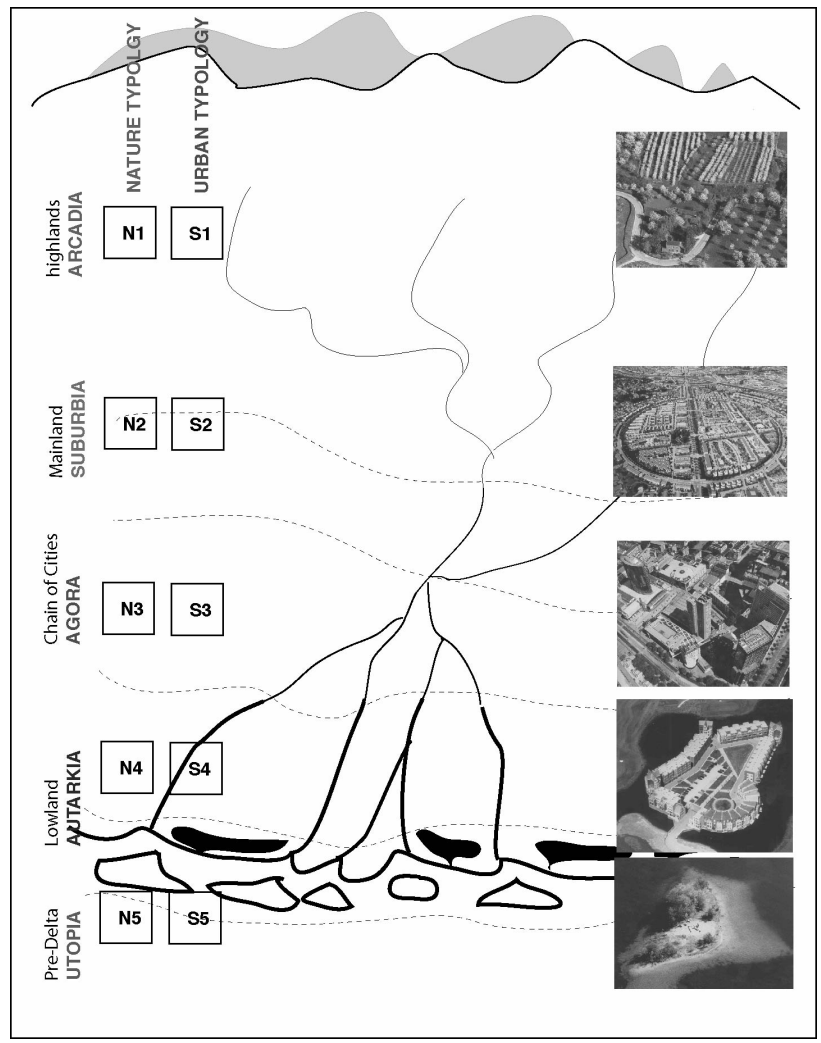

Figure 6: Diagram for the Toolkit for planning DELTA METROPOLIS.

\subsubsection{ARCADIA = planning for conservation}

Arcadia is characterized by a continuous small-scale development. Only catastrophes can produce serious changes. In such circumstances there is a need for clearness in decision making, strong local leaders and we will see appearing a competition between the local communities, keeping the local population alert and creating conditions for creative concurrency. There is a need for certainty about future developments. The local communities do prepare themselves in this respect.

This combination of factors may lead towards a planning style that does focus on conservation: conservation of local structures, of collective facilities at 
the local level, securization as for natural events, and no large scale disturbances of the instable local balances. One does have confidence in local leadership, there enough space for individual growth and creativity. Innovations are being avoided. One does not like experiments.

\subsubsection{SUBURBIA = planning for sustainable transformation}

Suburbia is characterized by high democratic virtues, necessary to secure the balances between the various interests (like struggle for space). Leaders are competent representatives of power, offering reference models for the developments of norms and values. There is a balanced development towards a stable future. And there is no need for destabilization by societal innovations. On the contrary, there is a need for securization of a large series of collective values: food, security, growth, and continuity.

In such an environment, there is a need for solid integrative long term planning instruments, like structure plans, on the regional scale. Here we have faith in democratic control by sound plans and political contracts. No individual competition, but reward-on-result tradition. There is also less affinity to hazardous experiments. Stable development is what we want here. Therefore we don't find much room for innovations.

\subsubsection{AGORA = development planning}

In Agora we find a dynamic social, cultural and economical climate. The power institutions do change rapidly. There is a strong competition between parties in the urban field, without emerging strong leaders. There is a permanent debate on evolution: the shouting party is the winning party in Agora. There is no clear view of whereto this development will lead. One is used to life in uncertainty, there is no consensus about the future.

In such a context, an open planning style is necessary, leaving enough space for unknown events. A social net is in place, recovering extreme abuses and substitution problems. There is a climate for strong competition, concurrence, substitution and personal profiling: "no plans but projects" is the local motto. Collective values are being secured by territorial legislation. There are optimal conditions for innovations and a large tolerance for surprising experiments.

\subsubsection{AUTARKIA $=$ no-planning}

In Autarkia we see a dynamic pattern in the social development. One is looking for adventure. There is a continuous confrontation between conservative (conservation of nature, of existing institutions like water management) and innovative forces (new visions on urbanization, on nature development, on health, on shopping, on leisure patterns). There is an urgent feeling for new social relationships, as a source for new communities on the new land. These communities are not based on stable values, but they face confidently the uncertain new future. Here we do find the same strong leadership, leaders with a clear view on the future, and with a charismatic influence on opinion and life style. There is more cohesion than competition.

No room for blueprint planning here. We have No-planning: space for community development, pioneers and experiments, with a large affinity towards 
self-steering and self-regulation. Such conditions do offer interesting lessons for Agora and Suburbia: Lowland is their laboratory. There is a favourable climate for openness, confidence and solidarity, with rather low degree of regulations and codes. In such a climate we find the right conditions for technological and social experiments and willingness for learning about success and failure factors.

\subsubsection{UTOPIA = blueprint planning}

In Utopia we find ourselves into the domain of technology and the large-scale innovation projects. Its all about the development of new forms of land development, creating sustainable environmental conditions for - at first stages technological innovations, while in latter stages there is more space available for social innovations in the form of pioneer settlements in new strongly controlled and managed conditions: safety, spatial planning, rentability are accepted and comprehensive planning goals. At the same time there are favourable conditions for new pioneer's nature: large areas, developing - under the same planning conditions - to sustainable natural landscapes.

In this environment, there is a need for blueprint planning, with a strongly defined long-term perspective, the domain of natural target typologies and appealing detailed futures. Technological innovations, under severe control, do take a central place in societal debate. In Utopia we have a total control society.

\subsection{Reflexion}

Above we did an attempt to organize dynamic interaction between spatial planning, landscape ecology and the culture of decision making, within the spatial framework of the Delta Metropolis. This did result in our proposition for a tool kit for planning the DELTA METROPOLIS.

Such an action is leading us towards a lot of borders in disciplines and knowledge domains. We are surely aware of the fact that this discourse does raise as many questions as it offers answers. But we do hope that a new domain can evolve out of the discussion: the domain of the relationship between the urban design concepts and the nature design concepts. We are convinced that in the Delta Metropolis both domains are strongly interrelated.

Summarizing:

1. Its worthwhile to consider Landscape as a basis for analysis of the green metropolis

2. It is obvious that Water is the main factor for analysis of Landscape

3. It is useful to design a typology of environments to connect ecological concepts to societal development

4. Nature and the City are connected fields of knowledge

5. Planning with Landscape allows selectivity in developing sustainable policies

\section{Acknowledgements}

With specials thanks to Madeleine van Mansfeld of Alterra, Wageningen, The Netherlands and Sjef Langeveld, Director of Both Ends, The Netherlands. 


\section{References}

[1] Aalbers, C.B.E.M. \& J.F. Jonkhof (Ed.). Planning on principle; S2N, the strategy of the two networks revisited. Aeneas Publishers, Boxtel (2003)

[2] Benevolo L. European cities (1968)

[3] Castells M. The rise of the network society. Blackwell (1996)

[4] Hall P. Technopoles of the World (with M. Castells (1994)

[5] Harvey D. In "Megacities Lecture 4: Possible Urban Worlds", Twynstra Gudde Management Consultants, Amersfoort, The Netherlands, (2000)

[6] Faludi AKF \& A. van der Valk. Rule and order: Dutch planning doctrine in the twentieth century. Kluwer Acd. Publ. 1994.

[7] Jonkhof J.F. Water bindt stad en land. In: Bouwen met water (building with water), Ter Poorten J.J. \& C. De Jong Red. V+K publishing (2003)

[8] Jonkhof J.F. \& N. van Ravesteyn. Plannen zonder plannen (Planning without plans) (Nova terra-3 2005)

[9] Jonkhof, J.F. \& S.P.Tjallingii. Stedelijke inrichting en water (Urban design and water). In: Alberts, F., M. Hidding \& M. van der Vlist, Ruimte en water, planningsopgaven voor een rode delta (Space and water, planning for a red delta). SDU uitgeverij (2003)

[10] Jonkhof J.F. \& M.P. Wijermans. Delta Metropolis: een grenzeloos gevarieerd parklandschap. In: M.Woestenburg, A. Buijs en W. Timmermans. Wie is er bang voor de stad. Blauwdruk (2003)

[11] Jonge De J.M. \& J.F. Jonkhof. Sturen door stimuleren, terugkijken en vooruitblikken (Governance by stimuli, looking back and looking forwards). Alterra-rapport nr 568, Wageningen (2002)

[12] Kuypers, V., J.F. Jonkhof, T. Ekamper, P. van Eijk \& S.P. Tjallingii. The PURE Guidebook on Planning with Water. Published by the Province of Groningen,. The Netherlands (2006)

[13] Kuypers. V. \& J.F.Jonkhof. Water en de stad, een LAT relatie (water and the city, living apart together) (Groen 4-2006)

[14] Olsen J. Culture of cities (1995)

[15] OMA/R.Koolhaas. Content. Taschen (2004)

[16] Schama S. The Embarrassment of Riches (1987)

[17] Schama S. Landscape \& Memory. Harper Collins (1995)

[18] Simmonds R. \& G. Hack ed. Global city regions. Spon 2000.

[19] Susteren A. Van, 2005. Metropolitan World Atlas. 010 publishers, Rotterdam

[20] Tjallingii, S.P. Ecological Conditions. PhD Thesis, Delft University of Technology. 1996 